\title{
Segmental chromosomal alterations lead to a higher risk of relapse in infants with MYCN-non-amplified localised unresectable/ disseminated neuroblastoma (a SIOPEN collaborative study)
}

\begin{abstract}
G Schleiermacher ${ }^{*, 1,2}$, J Michon ${ }^{2}$, A Ribeiro ${ }^{3}$, G Pierron $^{3}$, V Mosseri ${ }^{4}$, H Rubie $^{5}$, C Munzer $^{5}$, J Bénard $^{6}$, N Auger $^{6}$ V Combaret', I Janoueix-Lerosey', A Pearson ${ }^{8}$, DA Tweddle', N Bown ${ }^{10}, M_{\text {Gerrard }}{ }^{11}$, K Wheeler ${ }^{12}$, R Noguera ${ }^{13}$, E Villamon ${ }^{13}$, A Cañete ${ }^{14}$, Castel $^{14}$, B Marques ${ }^{15}$, A de Lacerda ${ }^{16}$, GP Tonini $^{17}$, K Mazzocco ${ }^{18}$, R Defferrari ${ }^{18}$, B de Bernardi ${ }^{19}$, A di Cataldo ${ }^{20}$, N van Roy ${ }^{21}$, B Brichard ${ }^{22}$, R Ladenstein ${ }^{23}$, I Ambros ${ }^{24}$, P Ambros ${ }^{24}$, K Beiske ${ }^{25}$, Delattre ${ }^{1,3}$ and J Couturier ${ }^{1,3}$

'INSERM U830, Laboratoire de Génétique et Biologie des Cancers, 26 rue d'Ulm, 75248 Paris Cedex 05, France; ${ }^{2}$ Département d'Oncologie Pédiatrique, Institut Curie, 26 rue d'Ulm, 75248 Paris Cedex 05, France; ${ }^{3}$ Unité de Génétique Somatique et Cytogénétique, Institut Curie, 26 rue d'Ulm 75248 Paris Cedex 05, France; ${ }^{4}$ Senvice de Biostatistiques, Institut Curie, 26 rue d'Ulm, 75248 Paris Cedex 05, France; ${ }^{5}$ Unité d'Hémato-Oncologie Pédiatrique, Hôpital des Enfants, 31059 Toulouse, France; ${ }^{6}$ Département de Biologie et de Pathologie Médicales, Service de Pathologie Moléculaire, Institut Gustave-Roussy, 94800 Villejuif, France; ${ }^{7}$ Laboratoire d'Oncologie Moléculaire, Centre Léon-Bérard, 69008 Lyon, France; ${ }^{8}$ Children's Department, Institute of Cancer Research, Royal Marsden Hospital, Sutton SM2 5 NG, UK; ${ }^{9}$ Northern Institute for Cancer Research, Newcastle University, Newcastle upon Tyne NE2 4HH, UK; ${ }^{10}$ Department of Human Genetics, Newcastle University, Newcastle upon Tyne NEI 3 BZ, UK; " Sheffield Children's Hospital, Sheffield SIO 2TH, UK; ${ }^{12}$ Paediatric Department of Haematology/Oncology, Children's Hospital, Oxford OX3 9DU, UK; ${ }^{13}$ Department of Pathology, University of Valencia, 46010 Valencia, Spain; ${ }^{14}$ Unidad de Oncología Pediátrica, Hospital Infantil La Fe, 46009 Valencia, Spain;

${ }^{15}$ Department of Genetics, National Institute of Health Dr Ricardo Jorge, $1649-016$ Lisboa, Portugal; ${ }^{16}$ Department of Pediatrics, Intituto Português de Oncologia Francisco Gentil, 1099-023 Lisboa, Portugal; ${ }^{17}$ Translational Oncopathology, National Cancer Research Institute, 16132 Genova, Italy;

${ }^{18}$ Laboratory of Italian Neuroblastoma Foundation, National Cancer Research Institute, 16132 Genova, Italy; ${ }^{19}$ Department of Paediatric Haematology and Oncology, Giannina Gaslini Children's Hospital, 16147 Genova, Italy; ${ }^{20}$ Department of Pediatric Hematology and Oncology, University of Catania, 95124 Catania, Italy; ${ }^{21}$ Center for Medical Genetics, Ghent University Hospital, 9000 Ghent, Belgium; ${ }^{22}$ Cliniques Universitaires Saint-Luc, Université Catholique de Louvain, 1348 Brussels, Belgium; ${ }^{23}$ St Anna Children's Hospital, SIRP-CCRI Studies and Statistics on Integrated Research and Projects, Children's Cancer Research Institute, Vienna, Austria; ${ }^{24}$ CCRI, Children's Cancer Research Institute, St. Anna Kinderkrebsforschung, 1090 Vienna, Austria; ${ }^{25}$ Department of Pathology, Oslo University Hospital, 0424 Oslo, Norway
\end{abstract}

BACKGROUND: In neuroblastoma (NB), the presence of segmental chromosome alterations (SCAs) is associated with a higher risk of relapse. METHODS: In order to analyse the role of SCAs in infants with localised unresectable/disseminated NB without MYCN amplification, we have performed an array $\mathrm{CGH}$ analysis of tumours from infants enroled in the prospective European INES trials.

RESULTS: Tumour samples from 218 out of 300 enroled patients could be analysed. Segmental chromosome alterations were observed in I 1\%, 20\% and 59\% of infants enroled in trials INES99.I (localised unresectable NB), INES99.2 (stage 4s) and INES99.3 (stage 4) (P<0.000 I). Progression-free survival was poorer in patients whose tumours harboured SCA, in the whole population and in trials INES99.I and INES99.2, in the absence of clinical symptoms (log-rank test, $P=0.000 \mathrm{I}, P=0.04$ and $P=0.0003$, respectively). In multivariate analysis, a SCA genomic profile was the strongest predictor of poorer progression-free survival.

CONCLUSION: In infants with stage 4s MYCN-non-amplified NB, a SCA genomic profile identifies patients who will require upfront treatment even in the absence of other clinical indication for therapy, whereas in infants with localised unresectable NB, a genomic profile characterised by the absence of SCA identifies patients in whom treatment reduction might be possible. These findings will be implemented in a future international trial.

British Journal of Cancer (201I) I 05, 1940-1948. doi:10.1038/bjc.2011.472 www.bjcancer.com

Published online 10 November 201 I

(c) 20I I Cancer Research UK

Keywords: neuroblastoma; infants; genomic profile; segmental chromosome alterations; prognosis

In neuroblastoma (NB), the most frequent solid extracranial cancer in childhood, characterised by substantial clinical heterogeneity, several recurrent genetic alterations have been shown

*Correspondence: Dr G Schleiermacher:

E-mail: gudrun.schleiermacher@curie.net

Revised 7 October 2011; accepted 12 October 2011; published online 10 November 2011 to be of prognostic impact (Maris et al, 2007; Janoueix-Lerosey et al, 2010; Maris, 2010). A near-triploid DNA content, on average reflecting whole chromosome gains, is frequently observed in lowstage tumours of younger children, and is associated with a favourable outcome (Ladenstein et al, 2001). On the other hand, MYCN amplification and segmental chromosome alterations (SCAs) most often involving chromosome regions $1 \mathrm{p}, 1 \mathrm{q}, 2 \mathrm{p}, 3 \mathrm{p}$, $4 \mathrm{p}, 11 \mathrm{q}$ and $17 \mathrm{q}$ are preferentially observed in advanced stages of 
disease in older children, and are associated with a poorer prognosis. These genetic parameters can now be analysed using genome-wide techniques such as array CGH or SNP arrays, clearly demonstrating that the genetic imbalances combine to define distinct genomic profiles (Vandesompele et al, 2005; George et al, 2007; Mosse et al, 2007; Schleiermacher et al, 2007; Tomioka et al, 2008; Janoueix-Lerosey et al, 2009). Indeed, the presence of SCAs, even in a background of numerical chromosome alterations (NCAs), is associated with a higher risk of relapse and a poorer outcome (Janoueix-Lerosey et al, 2009). Although risk stratification schemes have so far integrated molecular data based on only few chromosome loci (Cohn et al, 2009), more recent reports suggest that pangenomic data could further improve pretherapeutic risk estimation (Ambros et al, 2009; Janoueix-Lerosey et al, 2009; Caren et al, 2010). As high-risk NBs nearly always demonstrate SCA, future therapeutic strategies for these cases might rather rely on gene expression or other molecular data (Oberthuer et al, 2008; Vermeulen et al, 2009; Ambros et al, 2011). However, pangenomic data might prove to be especially informative for treatment stratification in the clinically defined low- and intermediate-risk groups (Janoueix-Lerosey et al, 2009; Schleiermacher et al, 2010). To date, the exact role of genomic imbalances in infants, particularly with localised unresectable/disseminated $\mathrm{NB}$, has not been reported.

The aim of this study was to analyse genetic alterations determined by array CGH in MYCN-non-amplified localised unresectable/disseminated NB of infants included in the prospective European INES99.1, INES99.2 and INES99.3 protocols (De Bernardi et al, 2009; Rubie et al, 2011) and to study the impact of the genomic profile on clinical characteristics and outcome in this population.

\section{PATIENTS AND METHODS}

\section{Patients}

Tumour samples from patients included in the INES99.1, INES99.2 and INES99.3 trials were included in this study (De Bernardi et al, 2009; Rubie et al, 2011) The INES trials, run by the Société Internationale d'Oncologie Pédiatrique-Europe Neuroblastoma (SIOPEN) in the participating countries Austria, Belgium, France, Italy, Norway, Portugal, Spain, Sweden and United Kingdom, recruited 300 infants aged $<12$ months diagnosed with a MYCN-non-amplified NB from 1999 to 2004. The INES99.1 trial proposed minimal upfront chemotherapy in infants with a localised unresectable NB with the aim to render these tumours resectable (Cecchetto et al, 2005; Rubie et al, 2011). The INES99.2 and INES99.3 trials proposed chemotherapy for infants with a disseminated NB, in case of life- or organ-threatening symptoms only in stage INSS $4 \mathrm{~s}$, or in case of metastases to the bone, lung or CNS (stage INSS 4), respectively (De Bernardi et al, 2009). Surgical resection of the primary tumour was performed in the absence of surgical risk factors (Cecchetto et al, 2005). In case of disease progression or relapse, individual therapeutic decisions were taken. The protocol was approved by local institutional review boards, and patients were enroled following written informed consent from parents or guardians. Median follow-up of these 300 patients was 60 months; 36 patients have had disease progression or relapse, and 9 patients have died ( 0 out of 119 in INES99.1, 7 out of 133 in INES99.2 and 2 out of 48 in INES99.3), with a 5-year progression-free survival (PFS) and overall survival (OS) of $87.8 \%$ $( \pm 1.9)$ and $97.5 \%( \pm 0.9)$, respectively.

\section{Pangenomic profile}

For a total of 218 out of 300 patients, array CGH was performed using DNA extracted from frozen tumour tissue obtained at diagnosis and harbouring $>50 \%$ tumour cells. Tumours from 93 out of 119 INES99.1, 93 out of 133 INES99.2 and 32 out of 48 INES99.3 patients could be analysed, with array CGH analysis results of 57 samples from French patients having been reported previously (Janoueix-Lerosey et al, 2009; Schleiermacher et al, 2010). For the remaining patients, either no tumour tissue was available or samples contained an insufficient amount of tumour cells or yielded poor-quality DNA not permitting interpretation of the array CGH result. The absence of MYCN amplification was confirmed by fluorescent in situ hybridisation in a national SIOPEN reference laboratory and centrally reviewed for all cases (Ambros et al, 2009). Among the 218 patients, there have been 30 relapses/progressions, and 5 patients have died.

Following standardised DNA extraction, samples were analysed by array CGH using for 185 cases an in-house BAC/PAC array with a genomic resolution of $\sim 1 \mathrm{Mb}$, as reported previously (Janoueix-Lerosey et al, 2009; Schleiermacher et al, 2010). Using a commercially available NimbleGen DNA array (Roche NimbleGen, Madison, WI, USA), 33 other cases were analysed, containing 72000 oligonucleotide probes, with an average resolution of $\sim 1$ probe per $40 \mathrm{~kb}$.

All obtained profiles were subjected to detailed visual inspection and analysed using the VAMP software (La Rosa et al, 2006). The smoothing algorithm GLAD (Hupe et al, 2004) was used to determine the status of the BAC or oligonucleotide probes (normal or altered ratios). A NCA was defined as probe ratios homogeneously altered throughout entire chromosomes, as compared with the median copy number across the genome. A SCA was defined by the presence of either at least 3 contiguous BAC or 100 contiguous oligonucleotide probes exhibiting a genomic status different from that of the rest of the chromosome.

A genomic type was attributed to all analysed samples, taking into account all observed genomic alterations, as described previously, with slight modifications (Janoueix-Lerosey et al, 2009; Schleiermacher et al, 2010). Cases presenting only NCA, without any SCA, were considered as having a 'NCA genomic profile'. Cases harbouring SCA, without or with NCA, were considered as having a 'SCA genomic profile'. Finally, cases in which no genetic changes were observed despite sufficient tumour cell content in the samples were termed 'silent' profiles.

The genomic profiles have been deposited in the NCBI Gene Expression Omnibus (Edgar et al, 2002) and are accessible through GEO Series accession number GSE26494 (http://www.ncbi.nlm. nih.gov/geo/query/acc.cgi?acc $=$ GSE26494).

\section{DNA index}

The cellular DNA content could be determined by flow or static cytometry in 108 cases. Tumours were classified as di-/tetraploid if the DNA index was $\leqslant 1.2$ or $\geqslant 1.8$. Tumours with a DNA index between 1.2 and 1.8 were termed pseudotriploid (Ladenstein $e t$ al, 2001).

\section{Statistical analysis}

Progression-free survival was defined as the time from diagnosis to first event (local or metastatic failure, either during treatment or after completion of treatment) or last follow-up. In patients with INSS stage $4 \mathrm{~s}$ disease without any specific treatment, progression was taken into account when occurring after 2 months of initial observation. Overall survival was defined as the time from diagnosis to death or last follow-up. Survival curves were analysed according to the Kaplan-Meier method and compared using the log-rank test. Multivariate analysis was performed using the Cox proportional-hazards regression model. Categorical variables were coded as a set of binary 'yes-no' variables. A backward modelbuilding procedure was used to identify the variables retained in the Cox model with a $P$-value of $\leqslant 0.05$. 


\section{RESULTS}

\section{Pangenomic profiling}

Of the 218 tumour samples analysed by array CGH, no copy number alterations could be detected in 8 cases. Among the remaining 210 cases, a NCA genomic profile was observed in 162 cases, whereas 48 tumours presented a SCA genomic profile (Figure 1). All cases with a SCA genomic profile harboured imbalances of chromosome regions recurrently altered in $\mathrm{NB}$ (gain of chromosome arms 1q, $2 \mathrm{p}$ or $17 \mathrm{q}$, loss of chromosome arms $1 \mathrm{p}, 3 \mathrm{p}, 4 \mathrm{p}, 11 \mathrm{q})$, except two cases showing imbalances in $14 \mathrm{q}$, and $4 \mathrm{q}$ and $6 \mathrm{p}$, respectively.

Among the 48 cases with a SCA genomic profile, the most frequent SCAs were gain of $17 q(81 \%)$, gain of $2 p(43 \%)$, loss of $1 \mathrm{p}(41 \%)$ and loss of $11 \mathrm{q}(39 \%)$ (Figure 1 and Table 1). For most chromosome arms harbouring recurrent imbalances, the breakpoints were scattered over large regions. However, for the 19 tumours harbouring distal $11 \mathrm{q}$ loss, breakpoints clustered within a smaller region of $12 \mathrm{Mb}$ (genome position $70-82 \mathrm{Mb}$; Supplementary Table 1 and Figure 2).

The frequency of the different genomic profiles was analysed in the different study groups, and their distribution in the different groups was not random. Indeed, in INES $99.1,11 \%$ of patients had SCA vs $20 \%$ in INES99.2 and 59\% in INES99.3 $\left(\chi^{2}\right.$-test, $P<0.0001$; Table 1). In patients with skin, liver or bone marrow metastases, the frequency of SCA was not significantly higher than in patients without such metastases (Figure 3 and Table 1). However, the single chromosome alterations $1 \mathrm{p}$ loss, $2 \mathrm{p}$ gain, $3 \mathrm{p}$ loss, $4 \mathrm{p}$ loss, $11 \mathrm{q}$ loss and $17 \mathrm{q}$ and a SCA genomic profile were observed more frequently in infants with radiologically confirmed bone metastases compared with those without bone lesions $\left(\chi^{2}\right.$-test, $P<0.0001$; Table 1).

Among the 108 cases for which ploidy data were available, 33 tumours were diploid/tetraploid and 75 pseudotriploid. The SCA profiles were observed more frequently, but not exclusively, in di/tetraploid tumours $\left(\chi^{2}\right.$-test, $P<0.0001$; Table 2$)$.

\section{Survival analysis}

The 5-year PFS and OS for the 218 patients were $86.2 \%( \pm 2.3)$ and $97.6 \%(+/ 1.0)$, respectively. Among the 5 patients who died of disease, 1 INES99.2 patient with a NCA genomic profile had bone, bone marrow and liver relapse 14 months after diagnosis, and died of disease 35 months after diagnosis, and 1 INES99.2 neonate with a NCA genomic profile died of fulminant disease shortly after diagnosis. Three other patients (2 INES99.2 and 1 INES99.3) with SCA genomic profiles had bone marrow/liver, bone/bone marrow and bone/skin relapse, and died of disease 10, 10 and 46 months after diagnosis, respectively (Table 3 ).

Further survival analyses concerned PFS only. The genetic markers $2 \mathrm{p}$ gain, $11 \mathrm{q}$ loss and $17 \mathrm{q}$ gain were all associated with a poorer PFS (Table 4). A SCA genomic profile was also strongly associated with a poorer PFS (Table 4 and Figure 4). Infants with a SCA genomic profile had a poorer PFS than those with a NCA genomic profile. Interestingly, the eight infants whose tumours had silent genomic profiles also fared worse.

A SCA genomic profile was associated with a poorer PFS in infants with localised unresectable (INES99.1) and with stage $4 \mathrm{~s}$ NB (INES99.2) (log-rank, $P=0.04$ and $P=0.0003$, respectively). Finally, among infants with stage 4 disease (INES99.3), no
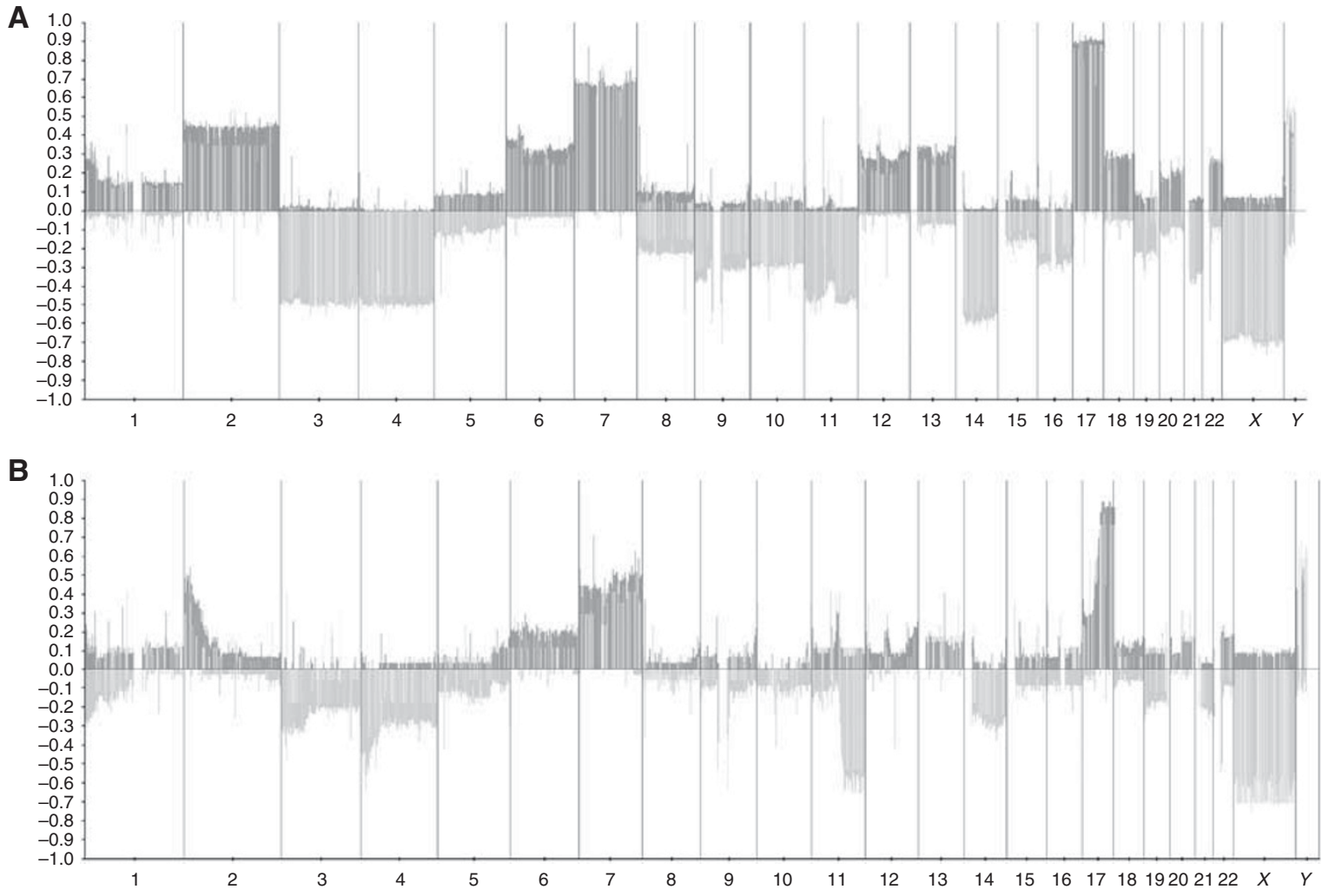

Figure I Frequencies of genome copy number gains ( $y$ axis, positive values, red) and losses ( $y$ axis, negative values, green) at each locus of the CGH array. Clones are ordered on the $x$ axis according to their position in the genome. Vertical grey lines correspond to chromosome separators. (A) Cases with a NCA genomic profile $(n=162)$ : presence of numerical chromosome alterations (NCAs) only. (B) Cases with a SCA genomic profile ( $n=48$ ): presence of segmental chromosomal alterations (SCAs) without or with NCA. The colour reproduction of this figure is available at the British journal of Cancer online. 
Table I Frequency of segmental chromosome alterations and genomic profiles according to the study groups and clinical characteristics

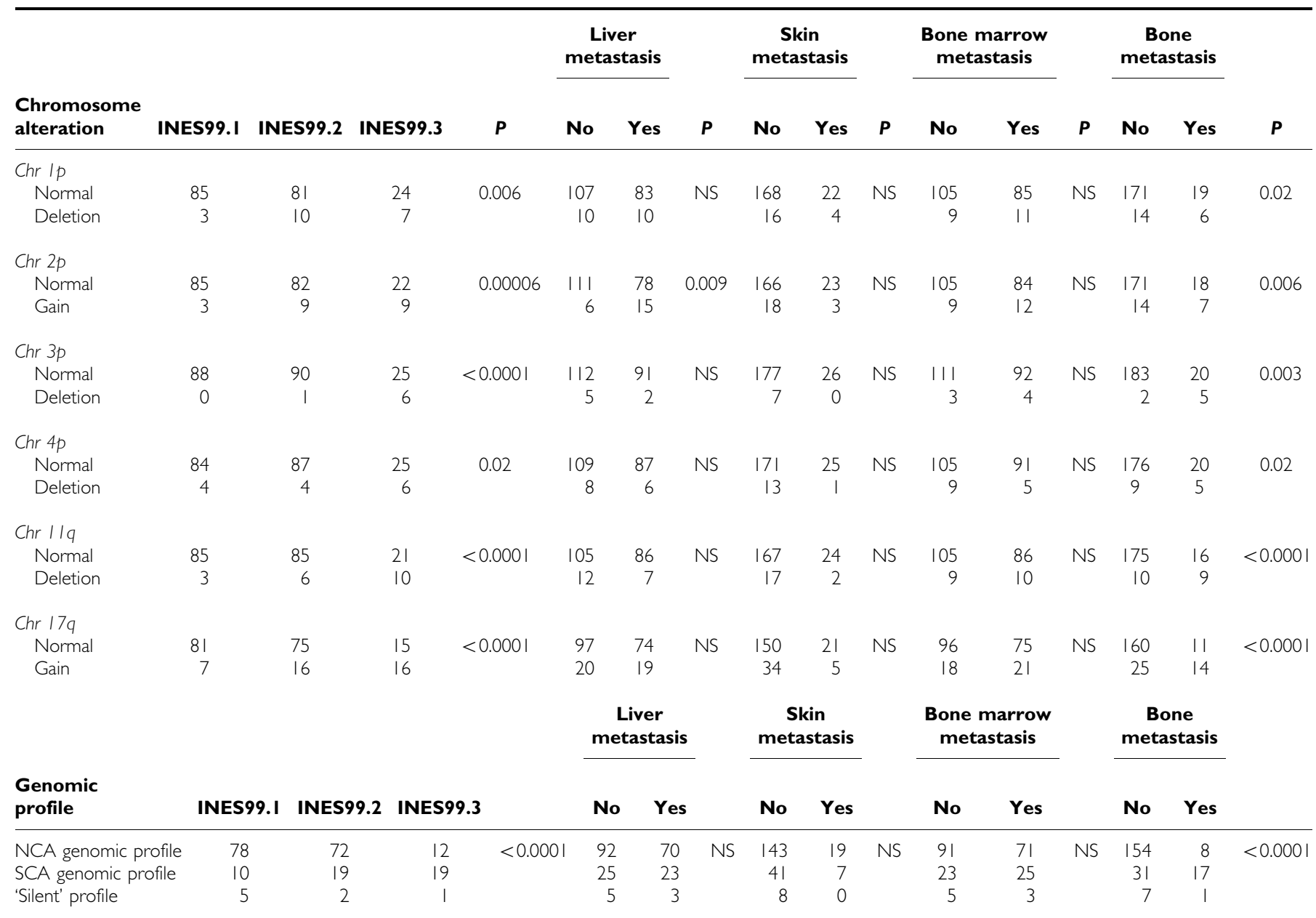

Abbreviations: $I N E S=$ Infant Neuroblastoma European Study; Chr=chromosome; NS= not significant; NCA = numerical chromosome alteration; SCA = segmental chromosome alteration. Cases with a 'silent' profile $(n=8)$ were excluded from the comparisons for single chromosome alterations. The data were analysed using the $\chi^{2}$-test, or Fisher's exact test if necessary.

statistically significant difference in PFS between patients with a NCA and SCA genomic profile was observed (Figure 4A-D). The DNA index was not of prognostic impact in the studied population.

\section{Multivariate analysis}

To determine which parameters independently predicted PFS, we applied the Cox proportional-hazards procedure including the 210 patients in whose tumours either NCA or SCA profiles had been identified, entering the variables genomic profile, single genetic alterations and treatment group. In a backward model, a SCA genomic profile was found to have a higher risk of relapse (hazard ratio: 5.24 , CI $2.4-11.4, P<0.0001$ ), whereas a lower risk of relapse was observed for treatment group INES99.3 (hazard ratio: 0.32, CI $0.094-1.11, P=0.076)$. The single genetic alterations were not retained in the model.

\section{Prognostic impact of genomic profiling in stage $4 \mathrm{~s}$ patients}

In patients with stage $4 \mathrm{~s}$ disease (trial INES99.2), treatment can be very heterogeneous, with a possibility of observation only, in the absence of clinical symptoms, or necessity of upfront chemotherapy in the presence of clinical symptoms, leading to very different total treatment burdens. We thus sought to analyse the impact of the genomic profile on treatment burden. Among 91 patients with stage $4 \mathrm{~s}$ disease, 40 patients had symptoms at diagnosis and thus received upfront medical treatment. In this group, no significant difference between PFS of the patients with NCA and typical SCA genomic profiles could be observed. However, for the 51 patients who did not have clinical symptoms at diagnosis and who initially did not receive upfront medical treatment, those with a SCA genomic profile had a significantly lower PFS than those with a NCA genomic profile (Figure $4 \mathrm{E}$ and $\mathrm{F}$ ).

Indeed, for stage $4 \mathrm{~s}$ patients, both among patients with NCA and with SCA tumours, $\sim 50 \%$ of the patients ( 43 out of 72 and 8 out of 19 patients, respectively; $\chi^{2}$ test not significant) did not require upfront chemotherapy, but had medical observation \pm surgical resection only, indicating that the clinical severity of disease was not worse at diagnosis in the SCA tumour group. However, once having relapsed, only 2 out of $6(33 \%)$ patients with a NCA profile received high-dose chemotherapy for salvage, whereas in the SCA tumour group, 5 out of $8(62 \%)$ patients received such treatment (Table 3).

\section{DISCUSSION}

In $\mathrm{NB}$, different recurrent genetic alterations combine to form distinct genomic types, which are in turn associated with different 
1944

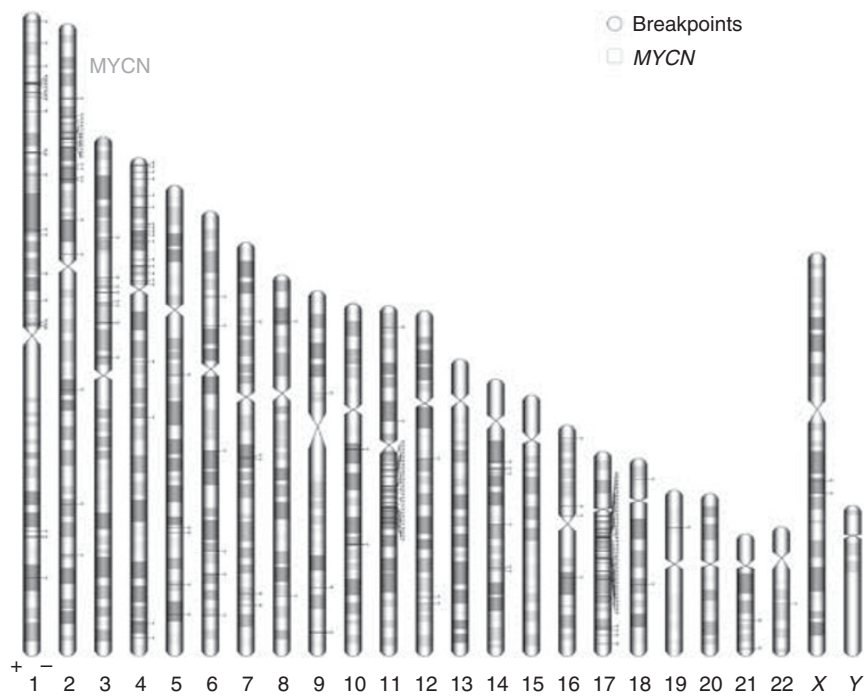

Figure 2 Localisation of breakpoints observed in 48 tumours harbouring SCA. Each breakpoint was localised according to the coordinates of the probe determining the left side of the breakpoint region, according to the Human Genome Draft Hgl8 (genome.ucsc.edu/goldenPath/ hgTracks.html). The graph was drawn using the web tool Idiographica (http://www.ncrna.org/idiographica/).
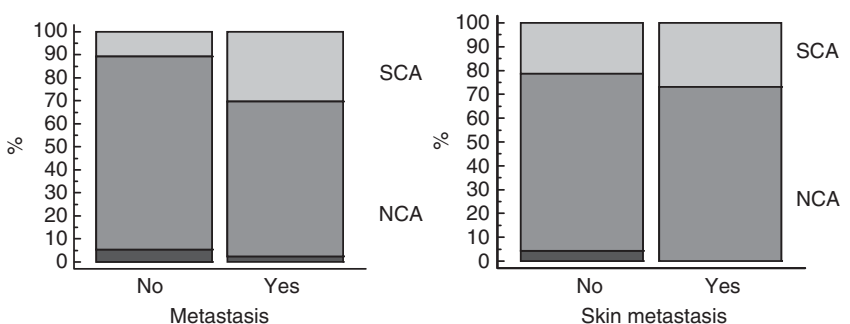

Liver metastasis

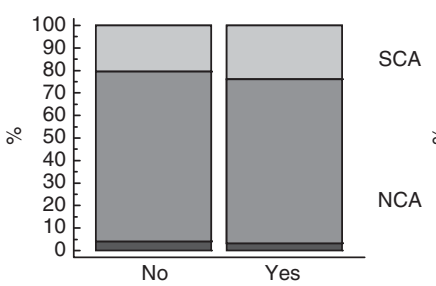

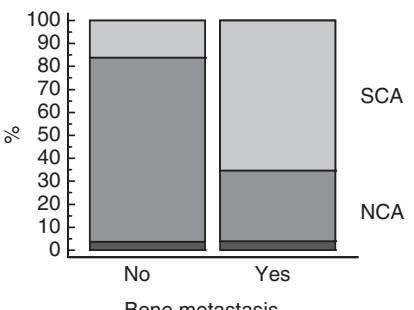

Bone metastasis
Figure 3 Frequency of genomic types according to the metastatic status (colour codes: dark grey: no genomic alterations; grey: NCA genomic profile; light grey: SCA genomic profile). Here, 38 out of 125 patients with metastases, 7 out of 26 patients with skin metastases and 23 out of 96 patients with liver metastasis had a SCA genomic profile vs 10 out of 93 patients without any metastases, 41 out of 192 patients without skin metastases and 25 out of 122 patients without liver metastases $\left(\chi^{2}\right.$ test, all NS). Finally, 17 out of 26 patients with radiologically defined bone metastases had a SCA genomic profile vs 31 out of 185 patients without bone metastasis $\left(\chi^{2}, P<0.000 \mathrm{I}\right)$.

Table 2 Repartition of the genomic profiles according to ploidy

Di/tetraploid Pseudotriploid P-value $\left(\chi^{2}\right)$

\begin{tabular}{lrrr}
\hline Numerical genomic profile & 16 & 65 & \\
Segmental genomic profile & 16 & 8 & \\
Silent profile & 1 & 2 & $P<0.000$ I \\
Total & 33 & 75 & \\
\hline
\end{tabular}

clinical outcomes. We have recently shown in a large patient cohort that the presence of SCA is associated with a poorer outcome, even when occurring together with $\mathrm{NCA}$, and that tumour progression is frequently associated with an accumulation of SCA, suggesting that SCA could be considered as surrogate markers for an underlying abnormality in a DNA maintenance or repair pathway (Janoueix-Lerosey et al, 2009; Schleiermacher et al, 2010). We have now explored the hypothesis that in infants with $M Y C N$-non-amplified localised unresectable/disseminated NB, pangenomic profiling might provide a useful prognostic marker.

In infants with NB without MYCN amplification, overall survival is, fortunately, high. However, in this patient population with a frequent indication for treatment even in newborns, it is crucial to consider treatment burden, as conventional chemotherapy courses, well tolerated in older children, can be associated with significant short- or long-term morbidity. It is thus important to fine-tune treatment indications for these patients in order to avoid over- or under-treatment. Considering that patients of this study have an excellent OS as previously reported (De Bernardi et al, 2009; Rubie et al, 2011), this study used PFS to determine if pangenomic profiling might be useful for therapeutic stratification in infants with MYCN-non-amplified localised unresectable/disseminated NB.

This study confirms recurrent SCA involving chromosome arms $1 p, 1 q, 2 p, 3 p, 4 p, 11 q$ and $17 q$ in NB, breakpoints in other chromosome arms being much rarer. The data are concordant with previous publications reporting a lower frequency of $1 \mathrm{p}$ deletion, $11 \mathrm{q}$ deletion or $17 \mathrm{q}$ gain in infants with localised $\mathrm{NB}$, and frequencies of $17 \mathrm{q}$ gain ranging from 50 to $70 \%$ in infants with stage $4 \mathrm{~s}$ or 4 disease (Spitz et al, 2006; Lavarino et al, 2009). However, previous studies did not take into account the whole genomic profile. We now show that a genomic profile characterised by the presence of SCA occurs in $11 \%$ of infants with localised unresectable NB, $20 \%$ of infants with stage $4 \mathrm{~s}$ and $59 \%$ of infants with stage $4 \mathrm{NB}$. A higher incidence of SCA was observed in older infants, and the median age at diagnosis was higher in infants with a SCA than those with a NCA genomic profile (6.7 vs 5.1 months at diagnosis, $t$-test, $P=0.006$ ).

In infants with disseminated $\mathrm{NB}$, the exact clinical delineation of INSS stage $4 \mathrm{~s} v s$ stage 4 has been controversial (Brodeur et al, 1993; Hero et al, 2008; Cohn et al, 2009; De Bernardi et al, 2009). It has been reported that infants with stage $4 \mathrm{~s}$ disease, including those with a primary tumour crossing the midline, or those with skeletal MIBG uptake in the absence of radiologically proven bone lesions, will require chemotherapy only in the presence of clinical symptoms (De Bernardi et al, 2009). We now show that in infants with NB, a SCA genomic profile is associated with metastatic disease and, in particular, bone metastasis. Furthermore, among 185 patients without bone metastasis at diagnosis, 3 out of 154 with a NCA genomic profile progressed with bone lesions $v s 6$ out of 31 with a SCA genomic profile. This observation leads to the hypothesis that the presence of SCA in NB cells might potentially increase their potential to metastasise to bone.

It has been suggested that $11 \mathrm{q}$ deletions might be associated with a particularly dismal outcome in older patients (Attiyeh et al, 2005; Caren et al, 2010). In this study, of the 5 patients who have died of disease, 2 had 11q deletion; and among 17 other patients whose tumours harboured 11q deletion, 5 have relapsed and could be salvaged, indicating that $11 \mathrm{q}$ deletion is not associated with a worse OS in infants.

Several recent studies, performed in large patient cohorts encompassing NB patients of all ages, have demonstrated that a genomic profile characterised by SCA is associated with a higher risk of relapse (Tomioka et al, 2008; Janoueix-Lerosey et al, 2009; Caren et al, 2010). We now show specifically in infants with $M Y C N$-non-amplified localised unresectable/disseminated NB, in a multivariate setting, that a SCA genomic profile is of prognostic importance, rather than single genetic alterations or clinical stage. No correlation between the size of the individual chromosome 
Table 3 Patients having relapsed, according to the protocol arm and genomic profile

\begin{tabular}{|c|c|c|c|c|c|c|c|}
\hline Protocol & $\begin{array}{l}\text { Clinical } \\
\text { presentation }\end{array}$ & $\begin{array}{l}\text { Genomic } \\
\text { profile }\end{array}$ & $\begin{array}{l}\text { Patient } \\
\text { number }\end{array}$ & $\begin{array}{l}\text { Site of } \\
\text { relapse }\end{array}$ & $\begin{array}{l}\text { Time from } \\
\text { diagnosis } \\
\text { to relapse } \\
\text { (months) }\end{array}$ & Treatment after relapse & $\begin{array}{l}\text { Outcome } \\
\text { (FU; months } \\
\text { from diagnosis) }\end{array}$ \\
\hline \multirow[t]{12}{*}{ INES99.I } & & Flat & 150 & PT & 16 & Surgery & CR (83) \\
\hline & & & 165 & PT, L, other & 1 & VP/Carbo $\times 4$ & CR (72) \\
\hline & & NCA genomic profile & 279 & PT, other & 13 & Surgery & Alive (69) \\
\hline & & & 100 & PT & 9 & Surgery, VP/Carbo $\times 2$ & Alive (59) \\
\hline & & & 124 & PT & 15 & Surgery & Alive (103) \\
\hline & & & 63 & PT & 1 & VPICarbo $\times 2$, CADO $\times 2$, surgery & CR (90) \\
\hline & & & 26 & $\mathrm{~L}$ & 4 & Unknown & Alive (52) \\
\hline & & & 31 & Other & 33 & Chemotherapy, surgery & Alive (96) \\
\hline & & & 168 & PT & 26 & Surgery, $R \times$ & CR (74) \\
\hline & & SCA genomic profile & 227 & PT & 19 & Surgery & Alive (67) \\
\hline & & & 235 & PT & 1 & VP/Carbo $\times 2$, CADO $\times 2$, surgery & $C R(64)$ \\
\hline & & & 144 & PT, LN & 3 & VP/Carbo $\times 2$, CADO $\times 2$, surgery & CR (85) \\
\hline \multirow[t]{15}{*}{ INES99.2 } & $\begin{array}{l}\text { No symptoms at diagnosis; } \\
\text { no upfront chemotherapy }\end{array}$ & Flat & 174 & PT, L & 3 & Surgery & CR (49) \\
\hline & & NCA genomic profile & 23 & $\mathrm{PT}, \mathrm{S}$ & 4 & VP/Carbo and CADO (6 courses) & CR (37) \\
\hline & & & 183 & $\mathrm{~L}$ & 3 & $\mathrm{VP} /$ Carbo $\times 3$ & CR (49) \\
\hline & & SCA genomic profile & 184 & $\mathrm{BM}, \mathrm{B}$ & 7 & $\begin{array}{l}\text { Topotecan-cyclophosphamide, ICE, } \\
\text { HD chemotherapy }\end{array}$ & CR (49) \\
\hline & & & 121 & $B, S$ & 4 & $\begin{array}{l}\text { VP/Carbo } \times 2 \text {, CADO } \times 2 \\
\text { VP cyclophosphamide }\end{array}$ & $\mathrm{DOD}(10)$ \\
\hline & & & 196 & $\mathrm{~L}$ & 7 & VP/Carbo $\times 2$, CADO $\times 1$ & Alive (37) \\
\hline & & & 14 & $\mathrm{~B}, \mathrm{BM}$ & 4 & $\mathrm{VP} /$ Carbo $\times 2$, CADO $\times 2$ & Alive (59) \\
\hline & & & 6 & $\mathrm{~B}, \mathrm{BM}$ & || & TVD, HD chemotherapy & Alive (73) \\
\hline & & & 89 & $\mathrm{PT}, \mathrm{B}, \mathrm{BM}, \mathrm{S}, \mathrm{L}, \mathrm{P}$ & 4 & VP/Carbo, HD chemotherapy, retinoic acid & CR (48) \\
\hline & $\begin{array}{l}\text { Symptoms at diagnosis, } \\
\text { requiring upfront } \\
\text { chemotherapy }\end{array}$ & NCA genomic profile & 118 & B & 7 & VP/Carbo, HD chemotherapy & CR (36) \\
\hline & & & $|1|$ & $B, B M, L$ & 14 & VP/Carbo, HD chemotherapy & DOD (35) \\
\hline & & & 61 & $L, B M, B, S, L N$ & 7 & VP/Carbo $\times 2, C A D O \times 2$ & CR (76) \\
\hline & & & 172 & PT, L & 0 & & $\mathrm{DOD}(0)$ \\
\hline & & SCA genomic profile & 75 & $B M, L$ & 41 & HD chemotherapy & $\mathrm{DOD}(48)$ \\
\hline & & & 109 & $B, L, P$ & 21 & HD chemotherapy & Alive (40) \\
\hline \multirow[t]{3}{*}{ INES99.3 } & & SCA genomic profile & 81 & B & 2 & Conventional chemotherapy & CR (5I) \\
\hline & & & 185 & $\mathrm{~B}, \mathrm{CNS}$ & 15 & Conventional chemotherapy & Alive (49) \\
\hline & & & 234 & $\mathrm{~B}, \mathrm{BM}$ & 9 & Conventional chemotherapy & $\operatorname{DOD}(10)$ \\
\hline
\end{tabular}

Abbreviations: INES = Infant Neuroblastoma European Study; PT = primary tumour; $S=$ skin; $B M=$ bone marrow; $B=$ bone; $L=$ liver; $P=$ pulmonary; $L N=$ lymph node; $\mathrm{CNS}=$ central nervous system; NCA = numerical chromosome alteration; SCA = segmental chromosome alteration; $C R=$ complete remission; $D O D=$ dead of disease; $\mathrm{FU}=$ follow-up; VP/Carbo = etoposide/carboplatin; $\mathrm{CADO}=$ cyclophosphamide/vincristin/doxorubicine; TVD = topothecan/vincristin/doxorubicine; ICE = ifosphamide/carboplatin/etoposide; $\mathrm{Rx}=$ radiotherapy; $\mathrm{HD}$ chemotherapy = high dose chemotherapy with autologous stem cell rescue.

Table 4 Prognostic impact of single genetic alterations and genomic profiles

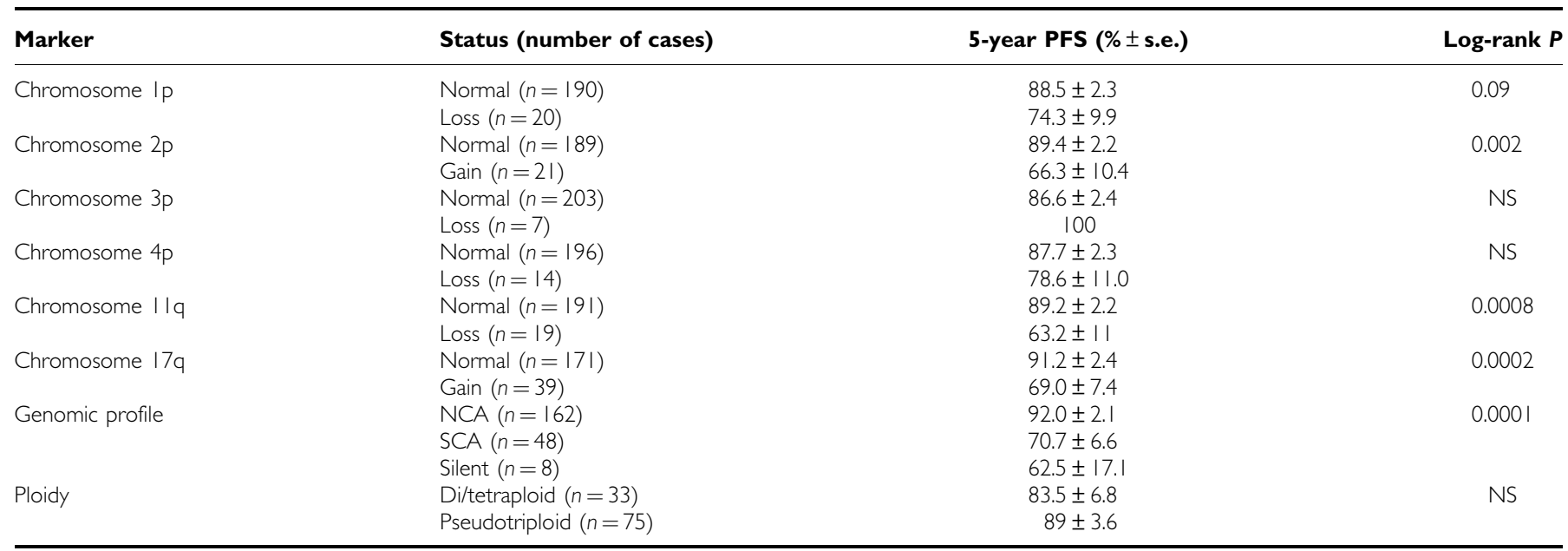

Abbreviations: PFS = progression-free survival; NS = not significant; NCA=numerical chromosome alteration; SCA=segmental chromosome alteration. For single chromosome alterations, cases with a 'silent' profile were not taken into account.

alterations and clinical outcome was observed (data not shown). The absence of prognostic impact of the clinical stage in a multivariate setting can probably be attributed to the more intensive chemotherapy for INES99.3 (INSS stage 4) patients, indicating that these patients are sufficiently treated with $4-8$ courses of chemotherapy (De Bernardi et al, 2009; Baker et al, 2010). The type 
A

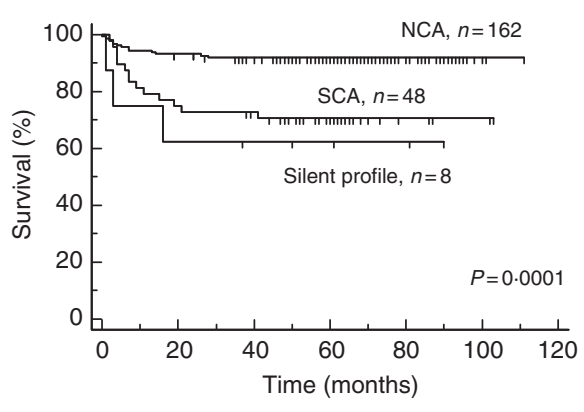

C

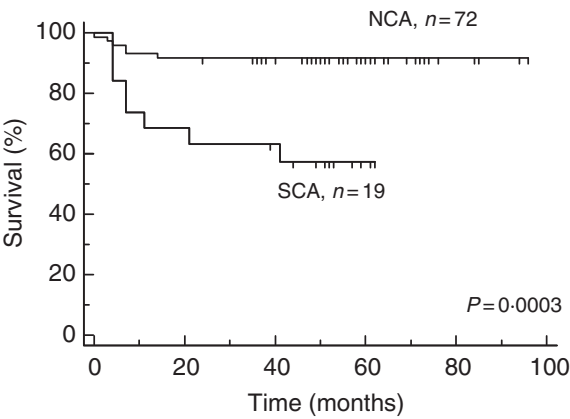

E

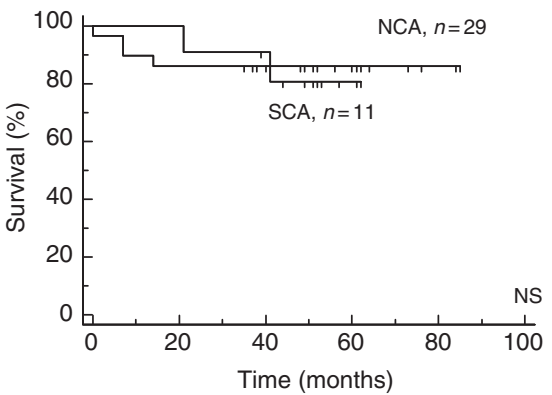

B

INES99.1

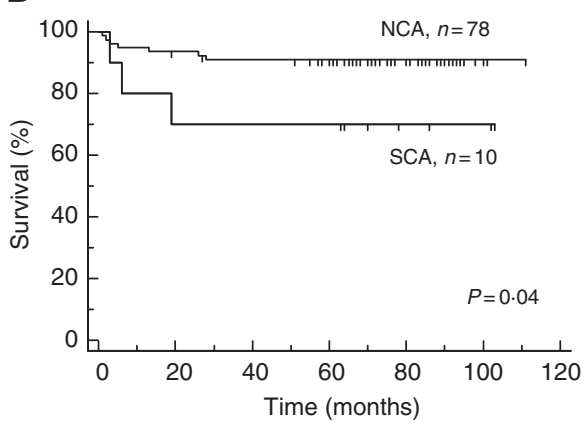

INES99.3

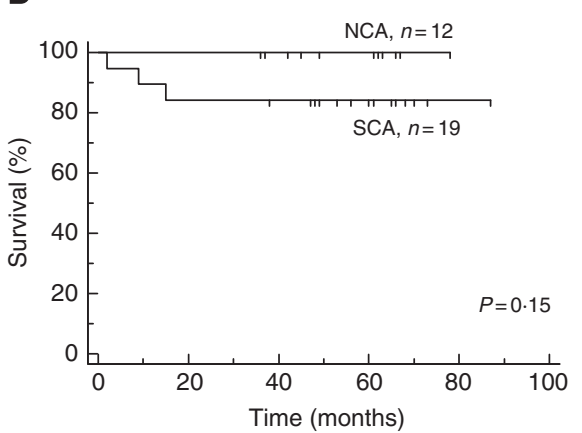

F

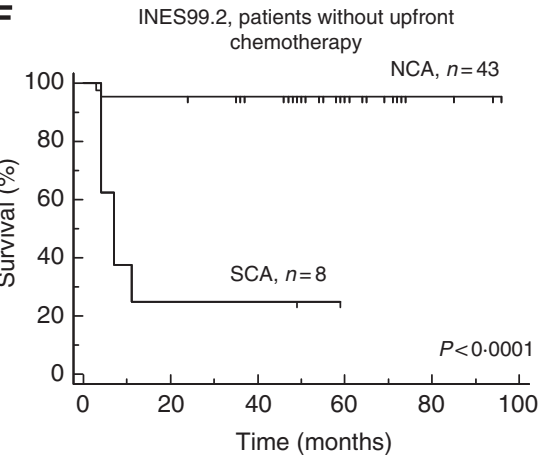

Figure 4 Kaplan-Meier survival analysis showing 5-year progression-free survival (PFS) according to the tumour genomic profile. (A) Among the whole study population $(n=218)$, the 5 -year PFS was $92 \%( \pm 2.1)$ in patients with a NCA genomic profile, $70.7 \%( \pm 6.6)$ in patients with a SCA genomic profile and $62.5 \%( \pm 17.1)$ in patients with a silent genomic profile (log-rank, $P=0.000 \mathrm{I})$. (B) Among infants with a localised unresectable NB (INES99.I), the 5 -year PFS was 91\% ( \pm 3.2$)$ in patients with a NCA genomic profile vs 70\% ( \pm | 4.5$)$ in patients with a SCA genomic profile (log-rank, $P=0.04)$. (C) Among infants with stage 4S NB (INES99.2), the 5-year PFS was 91.7\% ( \pm 3.2$)$ in patients with a NCA genomic profile vs 7\% ( \pm 11.5$)$ in patients with a SCA genomic profile (log-rank, $P=0.0003$ ). (D) Among infants with stage 4 NB (INES99.3), the 5 -year PFS was $100 \%$ in patients with a NCA genomic profile vs $84.2 \%( \pm 8.3)$ in patients with a SCA genomic profile (log-rank, not significant). (E) Among infants with stage 4s NB receiving upfront chemotherapy, the 5 -year PFS was $86.2 \%( \pm 6.4)$ in patients with a NCA genomic profile vs $80.8 \%$ ( \pm I 2.2) in patients with a SCA genomic profile (log-rank, NS). (F) Among infants with stage 4s NB not receiving upfront chemotherapy, the 5 -year PFS was $95.3 \%$ ( \pm 3.2 ) in patients with a NCA genomic profile vs $25 \%$ ( \pm I 5.3 ) in patients with a SCA genomic profile (log-rank, $P<0.000$ I).

of SCA to be taken into account for the definition of a SCA genomic profile remains controversial, with some recent data supporting the hypothesis that any SCA, whether occurring recurrently or not in $\mathrm{NB}$, may be associated with a poor outcome (Janoueix-Lerosey et al, 2009). In this series, only two tumours with a SCA genomic profile harboured only atypical imbalances, precluding from drawing any conclusion on their prognostic impact.

Interestingly, the infants with silent genomic profiles appeared to have a higher risk of relapse. For one sample, a DNA index of 1.46 was noted, indicating a perfect triploid chromosome content, in the context of which NCA might not be detected. On the other hand, it cannot be excluded that smaller alterations not detected by standard resolution arrays might be present in some NBs. The tumours of these patients will merit further exploration using higher-resolution techniques to search for as yet undetected genetic alterations.
Recent studies have enabled the identification of genomic loci associated with NB susceptibility at a constitutional level. These loci have been identified by genome-wide association studies (GWASs), using high-resolution SNP arrays. Common variants within the FLJ22536, BARD1 and LMO1 genes are significantly associated with susceptibility to high-risk NB, whereas SNPs within DUSP12, DDX4 and IL31RA are associated with less aggressive NB (Maris et al, 2008; Capasso et al, 2009; Diskin et al, 2009; Nguyen le et al, 2011; Wang et al, 2011). Constitutional copy number variations associated with NB susceptibility have been described for $L M O 1$ at 11p15.4 as well as the NBPF23 gene at 1q21.1 (Diskin et al, 2009; Wang et al, 2011). For the former, somatic copy number changes as whole chromosome arm 11p gain were observed in $12 \%$ of tumours, but only $5 \%$ showed interstitial gain of 11p15. In our study, focusing on genomic profiling of tumour DNA, the lower-resolution array CGH analysis did not 
detect any copy number alterations of interstitial chromosome regions surrounding the known susceptibility loci 1q21.1 and 11 p15.4.

The DNA index was not of prognostic impact in this study using previously published cutoffs. The exact definition of diploid vs pseudotriploid tumours based on DNA index remains controversial (Look et al, 1984; Ladenstein et al, 2001). When using a more restrictive DNA index cutoff of 1 to define diploid tumours, these 11 cases had a poorer PFS compared with the 97 others. However, a SCA genomic profile was associated with a higher risk of relapse even among patients whose tumours had a DNA index of $>1(P=0.002)$.

The prognostic impact of the genomic profile in infants with localised unresectable/disseminated NB without $M Y C N$ amplification is of high clinical importance. Indeed, the presence of a SCA genomic profile identifies stage $4 \mathrm{~s}$ NB patients with a higher risk of progression or relapse, for whom salvage therapy might have to be more intense, justifying more upfront treatment in patients who would otherwise receive little or no treatment (De Bernardi et al, 2009). On the other hand, a NCA genomic profile defines a population of infants with localised unresectable NB with a lower risk of disease progression. Thus, for infants with localised unresectable NB with a NCA profile, treatment reduction might be possible (Hero et al, 2008). These findings will be implemented in a future international trial.

\section{ACKNOWLEDGEMENTS}

In France, this work was supported by grants from the Institut National de la Santé et de la Recherche Médicale, the Ligue Nationale Contre le Cancer (Equipe labellisée) and the PHRC AOM 02014. The construction of the BAC/PAC array was supported by grants from the Carte d'Identite des Tumeurs programme of the Ligue Nationale Contre le Cancer. We thank the associations APAESIC (Association des Parents et des Amis des Enfants Soignés à l'Institut Curie), Association Hubert Gouin, 'Les Bagouz à Manon' and 'Enfants et Santé'. We also thank Ms Sandrine Damerval-Ferrand for excellent technical assistance and Philippe La Rosa for help in the preparation of figures. In Spain, this work was furthermore supported by the following grants: RD06/0020/ 0102 from RTICC, ISCIII and ERDF and 396/2009 from FAECC. In Italy, RD and KM are fellows of the Italian Neuroblastoma Foundation. We also thank the Italian Neuroblastoma Foundation.

Supplementary Information accompanies the paper on British Journal of Cancer website (http://www.nature.com/bjc)

\section{REFERENCES}

Ambros IM, Brunner B, Aigner G, Bedwell C, Beiske K, Benard J, Bown N, Combaret V, Couturier J, Defferrari R, Gross N, Jeison M, Lunec J, Marques B, Martinsson T, Mazzocco K, Noguera R, Schleiermacher G, Speleman F, Stallings R, Tonini GP, Tweddle DA, Valent A, Vicha A, Roy NV, Villamon E, Ziegler A, Preuner S, Drobics M, Ladenstein R, Amann G, Schuit RJ, Potschger U, Ambros PF (2011) A multilocus technique for risk evaluation of patients with neuroblastoma. Clin Cancer Res 17: 792-804

Ambros PF, Ambros IM, Brodeur GM, Haber M, Khan J, Nakagawara A, Schleiermacher G, Speleman F, Spitz R, London WB, Cohn SL, Pearson $\mathrm{AD}$, Maris JM (2009) International consensus for neuroblastoma molecular diagnostics: report from the International Neuroblastoma Risk Group (INRG) Biology Committee. $\mathrm{Br} J$ Cancer 100: $1471-1482$

Attiyeh EF, London WB, Mosse YP, Wang Q, Winter C, Khazi D, McGrady PW, Seeger RC, Look AT, Shimada H, Brodeur GM, Cohn SL, Matthay KK, Maris JM (2005) Chromosome 1p and 11q deletions and outcome in neuroblastoma. N Engl J Med 353: 2243-2253

Baker DL, Schmidt ML, Cohn SL, Maris JM, London WB, Buxton A, Stram D, Castleberry RP, Shimada H, Sandler A, Shamberger RC, Look AT, Reynolds CP, Seeger RC, Matthay KK (2010) Outcome after reduced chemotherapy for intermediate-risk neuroblastoma. $N$ Engl J Med 363: $1313-1323$

Brodeur GM, Pritchard J, Berthold F, Carlsen NL, Castel V, Castelberry RP, De Bernardi B, Evans AE, Favrot M, Hedborg F, Kaneko M, Kamshead J, Lampert F, Lee REJ, Look T, Pearson ADJ, Philip T, Roald B, Sawada T, Seeger R, Tsuchida Y, Voute PA (1993) Revisions of the international criteria for neuroblastoma diagnosis, staging, and response to treatment. J Clin Oncol 11: 1466-1477

Capasso M, Devoto M, Hou C, Asgharzadeh S, Glessner JT, Attiyeh EF, Mosse YP, Kim C, Diskin SJ, Cole KA, Bosse K, Diamond M, Laudenslager $M$, Winter $C$, Bradfield JP, Scott RH, Jagannathan J, Garris M, McConville C, London WB, Seeger RC, Grant SF, Li H, Rahman N, Rappaport E, Hakonarson H, Maris JM (2009) Common variations in BARD1 influence susceptibility to high-risk neuroblastoma. Nat Genet 41: $718-723$

Caren H, Kryh H, Nethander M, Sjoberg RM, Trager C, Nilsson S, Abrahamsson J, Kogner P, Martinsson T (2010) High-risk neuroblastoma tumors with $11 \mathrm{q}$-deletion display a poor prognostic, chromosome instability phenotype with later onset. Proc Natl Acad Sci USA 107: $4323-4328$

Cecchetto G, Mosseri V, De Bernardi B, Helardot P, Monclair T, Costa E, Horcher E, Neuenschwander S, Toma P, Rizzo A, Michon J, Holmes K (2005) Surgical risk factors in primary surgery for localized neuroblas- toma: the LNESG1 study of the European International Society of Pediatric Oncology Neuroblastoma Group. J Clin Oncol 23: $8483-8489$

Cohn SL, Pearson AD, London WB, Monclair T, Ambros PF, Brodeur GM, Faldum A, Hero B, Iehara T, Machin D, Mosseri V, Simon T, Garaventa A, Castel V, Matthay KK (2009) The International Neuroblastoma Risk Group (INRG) classification system: an INRG Task Force report. J Clin Oncol 27: 289-297

De Bernardi B, Gerrard M, Boni L, Rubie H, Canete A, Di Cataldo A, Castel V, Forjaz de Lacerda A, Ladenstein R, Ruud E, Brichard B, Couturier J, Ellershaw C, Munzer C, Bruzzi P, Michon J, Pearson AD (2009) Excellent outcome with reduced treatment for infants with disseminated neuroblastoma without MYCN gene amplification. J Clin Oncol 27: $1034-1040$

Diskin SJ, Hou C, Glessner JT, Attiyeh EF, Laudenslager M, Bosse K, Cole K, Mosse YP, Wood A, Lynch JE, Pecor K, Diamond M, Winter C, Wang K, Kim C, Geiger EA, McGrady PW, Blakemore AI, London WB, Shaikh TH, Bradfield J, Grant SF, Li H, Devoto M, Rappaport ER, Hakonarson H, Maris JM (2009) Copy number variation at 1q21.1 associated with neuroblastoma. Nature 459: 987 -991

Edgar R, Domrachev M, Lash AE (2002) Gene Expression Omnibus: NCBI gene expression and hybridization array data repository. Nucleic Acids Res 30: $207-210$

George RE, Attiyeh EF, Li S, Moreau LA, Neuberg D, Li C, Fox EA, Meyerson M, Diller L, Fortina P, Look AT, Maris JM (2007) Genomewide analysis of neuroblastomas using high-density single nucleotide polymorphism arrays. PLoS One 2: e255

Hero B, Simon T, Spitz R, Ernestus K, Gnekow AK, Scheel-Walter HG, Schwabe D, Schilling FH, Benz-Bohm G, Berthold F (2008) Localized infant neuroblastomas often show spontaneous regression: results of the prospective trials NB95-S and NB97. J Clin Oncol 26: 1504-1510

Hupe P, Stransky N, Thiery JP, Radvanyi F, Barillot E (2004) Analysis of array CGH data: from signal ratio to gain and loss of DNA regions. Bioinformatics 20: $3413-3422$

Janoueix-Lerosey I, Schleiermacher G, Delattre O (2010) Molecular pathogenesis of peripheral neuroblastic tumors. Oncogene 29: 1566-1579

Janoueix-Lerosey I, Schleiermacher G, Michels E, Mosseri V, Ribeiro A, Lequin D, Vermeulen J, Couturier J, Peuchmaur M, Valent A, Plantaz D, Rubie H, Valteau-Couanet D, Thomas C, Combaret V, Rousseau R, Eggert A, Michon J, Speleman F, Delattre O (2009) Overall genomic pattern is a predictor of outcome in neuroblastoma. J Clin Oncol 27: $1026-1033$

Ladenstein R, Ambros IM, Potschger U, Amann G, Urban C, Fink FM, Schmitt K, Jones R, Slociak M, Schilling F, Ritter J, Berthold F, Gadner H, 
Ambros PF (2001) Prognostic significance of DNA di-tetraploidy in neuroblastoma. Med Pediatr Oncol 36: 83-92

La Rosa P, Viara E, Hupe P, Pierron G, Liva S, Neuvial P, Brito I, Lair S, Servant N, Robine N, Manie E, Brennetot C, Janoueix-Lerosey I, Raynal V, Gruel N, Rouveirol C, Stransky N, Stern MH, Delattre O, Aurias A, Radvanyi F, Barillot E (2006) VAMP: visualization and analysis of array-CGH, transcriptome and other molecular profiles. Bioinformatics 22: 2066-2073

Lavarino C, Cheung NK, Garcia I, Domenech G, de Torres C, Alaminos M, Rios J, Gerald WL, Kushner B, LaQuaglia M, Mora J (2009) Specific gene expression profiles and chromosomal abnormalities are associated with infant disseminated neuroblastoma. BMC Cancer 9: 44

Look AT, Hayes FA, Nitschke R, McWilliams NB, Green AA (1984) Cellular DNA content as a predictor of response to chemotherapy in infants with unresectable neuroblastoma. $N$ Engl J Med 311: 231-235

Maris JM (2010) Recent advances in neuroblastoma. N Engl J Med 362: $2202-2211$

Maris JM, Hogarty MD, Bagatell R, Cohn SL (2007) Neuroblastoma. Lancet 369: $2106-2120$

Maris JM, Mosse YP, Bradfield JP, Hou C, Monni S, Scott RH, Asgharzadeh S, Attiyeh EF, Diskin SJ, Laudenslager M, Winter C, Cole KA, Glessner JT, Kim C, Frackelton EC, Casalunovo T, Eckert AW, Capasso M, Rappaport EF, McConville C, London WB, Seeger RC, Rahman N, Devoto M, Grant SF, Li H, Hakonarson H (2008) Chromosome 6p22 locus associated with clinically aggressive neuroblastoma. $N$ Engl J Med 358: 2585-2593

Mosse YP, Diskin SJ, Wasserman N, Rinaldi K, Attiyeh EF, Cole K, Jagannathan J, Bhambhani K, Winter C, Maris JM (2007) Neuroblastomas have distinct genomic DNA profiles that predict clinical phenotype and regional gene expression. Genes Chromosomes Cancer 46: 936-949

Nguyen le B, Diskin SJ, Capasso M, Wang K, Diamond MA, Glessner J, Kim C, Attiyeh EF, Mosse YP, Cole K, Iolascon A, Devoto M, Hakonarson H, Li HK, Maris JM (2011) Phenotype restricted genome-wide association study using a gene-centric approach identifies three low-risk neuroblastoma susceptibility loci. PLoS Genet 7: e1002026

Oberthuer A, Kaderali L, Kahlert Y, Hero B, Westermann F, Berthold F, Brors B, Eils R, Fischer M (2008) Subclassification and individual survival time prediction from gene expression data of neuroblastoma patients by using CASPAR. Clin Cancer Res 14: 6590-6601

Rubie H, De Bernardi B, Gerrard M, Canete A, Ladenstein R, Couturier J, Ambros P, Munzer C, Pearson AD, Garaventa A, Brock P, Castel V, Valteau-Couanet D, Holmes K, Di Cataldo A, Brichard B, Mosseri V, Marquez C, Plantaz D, Boni L, Michon J (2011) Excellent outcome with reduced treatment in infants with nonmetastatic and unresectable neuroblastoma without MYCN amplification: results of the prospective INES 99.1. J Clin Oncol 29: 449-455

Schleiermacher G, Janoueix-Lerosey I, Ribeiro A, Klijanienko J, Couturier J, Pierron G, Mosseri V, Valent A, Auger N, Plantaz D, Rubie H, Valteau-Couanet D, Bourdeaut F, Combaret V, Bergeron C, Michon J, Delattre O (2010) Accumulation of segmental alterations determines progression in neuroblastoma. J Clin Oncol 28: 3122-3130

Schleiermacher G, Michon J, Huon I, d'Enghien CD, Klijanienko J, Brisse H, Ribeiro A, Mosseri V, Rubie H, Munzer C, Thomas C, Valteau-Couanet D, Auvrignon A, Plantaz D, Delattre O, Couturier J (2007) Chromosomal CGH identifies patients with a higher risk of relapse in neuroblastoma without MYCN amplification. Br J Cancer 97: 238-246

Spitz R, Hero B, Simon T, Berthold F (2006) Loss in chromosome 11q identifies tumors with increased risk for metastatic relapses in localized and 4 S neuroblastoma. Clin Cancer Res 12: 3368-3373

Tomioka N, Oba S, Ohira M, Misra A, Fridlyand J, Ishii S, Nakamura Y, Isogai E, Hirata T, Yoshida Y, Todo S, Kaneko Y, Albertson DG, Pinkel D, Feuerstein BG, Nakagawara A (2008) Novel risk stratification of patients with neuroblastoma by genomic signature, which is independent of molecular signature. Oncogene 27: 441-449

Vandesompele J, Baudis M, De Preter K, Van Roy N, Ambros P, Bown N, Brinkschmidt C, Christiansen H, Combaret V, Lastowska M, Nicholson J, O'Meara A, Plantaz D, Stallings R, Brichard B, Van den Broecke C, De Bie S, De Paepe A, Laureys G, Speleman F (2005) Unequivocal delineation of clinicogenetic subgroups and development of a new model for improved outcome prediction in neuroblastoma. J Clin Oncol 23: $2280-2299$

Vermeulen J, De Preter K, Naranjo A, Vercruysse L, Van Roy N, Hellemans J, Swerts K, Bravo S, Scaruffi P, Tonini GP, De Bernardi B, Noguera R, Piqueras $\mathrm{M}$, Canete A, Castel V, Janoueix-Lerosey I, Delattre O, Schleiermacher G, Michon J, Combaret V, Fischer M, Oberthuer A, Ambros PF, Beiske K, Benard J, Marques B, Rubie H, Kohler J, Potschger U, Ladenstein R, Hogarty MD, McGrady P, London WB, Laureys G, Speleman F, Vandesompele J (2009) Predicting outcomes for children with neuroblastoma using a multigene-expression signature: a retrospective SIOPEN/COG/GPOH study. Lancet Oncol 10: 663-671

Wang K, Diskin SJ, Zhang H, Attiyeh EF, Winter C, Hou C, Schnepp RW, Diamond M, Bosse K, Mayes PA, Glessner J, Kim C, Frackelton E, Garris M, Wang Q, Glaberson W, Chiavacci R, Nguyen L, Jagannathan J, Saeki N, Sasaki H, Grant SF, Iolascon A, Mosse YP, Cole KA, Li H, Devoto M, McGrady PW, London WB, Capasso M, Rahman N, Hakonarson H, Maris JM (2011) Integrative genomics identifies LMO1 as a neuroblastoma oncogene. Nature 469: 216-220

This work is published under the standard license to publish agreement. After 12 months the work will become freely available and the license terms will switch to a Creative Commons Attribution-NonCommercial-Share Alike 3.0 Unported License. 